\title{
Heart transplantation in patients who have congenital heart disease and single-lung physiology
}

\author{
Aditya K. Kaza, MD \\ From the Department of Cardiac Surgery, Boston Children's Hospital; and the Department of Surgery, Harvard \\ Medical School, Boston, Mass. \\ Disclosures: Author has nothing to disclose with regard to commercial support. \\ Received for publication June 20, 2015; accepted for publication June 23, 2015; available ahead of print July 22, \\ 2015. \\ Address for reprints: Aditya K. Kaza, MD, Department of Cardiac Surgery, Boston Children's Hospital, 300 \\ Longwood Ave, Bader 273, Boston, MA 02115 (E-mail: aditya.kaza@cardio.chboston.org). \\ J Thorac Cardiovasc Surg 2015;150:1473 \\ $0022-5223 / \$ 36.00$ \\ Copyright $(2015$ by The American Association for Thoracic Surgery \\ http://dx.doi.org/10.1016/j.jtcvs.2015.06.054
}

Zuckerman and colleagues ${ }^{1}$ present their experience with heart transplantation in patients with single-lung physiology. This series includes 22 patients who underwent heart transplantation over a period of 3 decades. This cohort included 14 patients with single-ventricle physiology, 7 with tetralogy of Fallot, and 1 with uncorrected d-transposition of the great arteries with ventricular septal defect. Looking at the single-ventricle patients, 11 had superior cavopulmonary connection, and 2 had total cavopulmonary connection. The anatomic basis for the resultant single-lung physiology was variable in the series; some patients had congenital and acquired pulmonary artery discontinuity; some had anatomic continuity. The patient group is very complex, from both an anatomic standpoint and a pulmonary vascular resistance standpoint. The authors report remarkable outcomes in these patients. The outcomes are a testament to their excellent perioperative management of these patients.

I am particularly interested in the single-ventricle patients in this series. Significant challenges are associated with managing patients who have univentricular physiology and develop single-lung physiology. Reports such as this show the feasibility of doing heart transplantation; others have done completion cavopulmonary connection in single-lung patients. ${ }^{2}$ A potentially informative next step is examination of the etiology of acquired unilateral pulmonary atresia, and development of strategies to prevent this anatomic issue.

The authors mention using lung-perfusion scans sparingly; however, at Boston Children's Hospital, we use screening lung-perfusion scans regularly. We find this approach to be extremely helpful in assessing pulmonary flow distribution and determining if intervention is necessary. In addition, we use this modality to assess the outcomes of angioplasty interventions performed in either the catheterization laboratory or the operating room. group.

\section{References} Surg. 2012;94:1275-80.

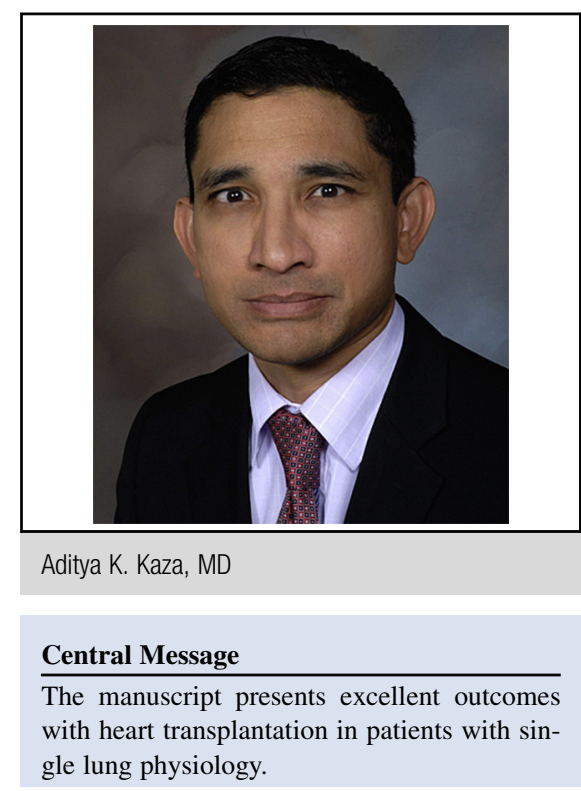

See Article page 1465.

Finally, we are developing techniques to help rehabilitate the "problematic branch pulmonary artery" in patients with single-ventricle physiology. A few of these patients have flow reversal in 1 of the branch pulmonary arteries, secondary to anatomic reasons and/or collateral burden. Our strategy to rehabilitate these pulmonary arteries includes performing an aortopulmonary shunt to the problematic pulmonary artery and placing a band/barrier between the branch pulmonary arteries to help prevent backflow into the cavopulmonary circuit. The theory behind this approach is that robust antegrade flow in the branch pulmonary arteries would cause regression of the microvascular collateral flow. The hope is that novel solutions such as this can prevent acquisition of single-lung physiology and subsequent cardiac failure. In conclusion, the authors ${ }^{1}$ are to be commended on their excellent results with heart transplantation in this very complex patient

1. Zuckerman WA, Richmond ME, Lee TM, Bacha EA, Chai PJ, Chen JM, et al. Heart transplantation in the setting of complex congenital heart disease and physiologic single lung. J Cardiovasc Thorac Surg. 2015;150:1465-72.

2. Fujii Y, Sano S, Asou T, Imoto Y, Oshima Y, Kawasaki S, et al. Outcomes of one-lung Fontan operation: a retrospective multicenter study in Japan. Ann Thorac 